\title{
A Retrospective Study on Presentation, Patterns, and the Prevalence of Injuries in Alleged Sexual Assault Cases, Presented to District General Hospital Gampaha from July 2018 to April 2019
}

Perera BCS*

Office of the Judicial Medical Officer, District Base Hospital, Dambulla, Sri Lanka

\begin{abstract}
Introduction: Sexual abuse is an undesired sexual behavior by one person upon another. In Sri Lanka, all sexual abuse cases are expected to be examined by a medico-legal specialist before the court procedure. This study was conducted to identify the presentation, pattern, and prevalence of injuries among the sexual abuse victims presented to District General Hospital Gampaha. The findings of this study will help to improve the knowledge on different variables that can influence or affect the medico-legal opinion, and the management of victims including prevention.
\end{abstract}

Methodology: A retrospective descriptive study was conducted using medico-legal records of all the cases with alleged sexual abuse reported to DGH Gampaha, during the 10 months from July 2018 to April 2019. Data were analyzed using Statistical Package for Social Sciences (SPSS) version 26 with descriptive statistics. Bivariate analysis and multiple logistic regression model used where necessary.

Results: A total of 103 alleged sexual assault cases were assessed with $85 \%$ females, and remaining $15 \%$ were male victims. The median age of victims was 15 years. Almost all the perpetrators were males and the mean age is 31 years. There was $92 \%$ probability of an abuser become a known person or a relative of the victim. Ten percent $(10 \%)(n=10)$ of victims sustained non-genital injuries following a sexual assault with injuries in more than one site and $11 \%(n=11)$ victims had genital injuries. About $40 \%(n=40)$ of victims gave a history of repeated abuse with no statistically significant difference among the genders (chi-square $=2.6, p=0.105>0.05$ ). On multiple logistics regression, those who had a history of repeated abuse and who became pregnant following the abuse were significantly associated with the length of time to reporting $(\operatorname{Exp}(B)=3.082 ; 95 \% \mathrm{CI}, 1.224-7.76$; p-value $=$ $0.017<0.05$ and $(\operatorname{Exp}(B)=17.066 ; 95 \%$ CI, $2.001-145.56$, p-value $=0.009<0.05)$ respectively). Sexually assaulted unmarried females have a 13\% (95\% Confidence interval, $06 \%$ - 22\%) chance of getting pregnant.

Conclusion: Female sex, and less than 16 years of age, is the most vulnerable group. Early adolescents had comparatively higher genital injury prevalence. Also, the genital injury prevalence was almost four-fold among the victims that presented to the medicolegal examination within one week or less. All the victims, who had anal/perianal injuries, were less than 15-year-old males. History of repeated abuse and presence of pregnancy was significantly associated with the duration of time to report to the hospital. $13 \%$ of sexually assaulted unmarried females being presented with pregnancy, is an alarming finding and needs evaluation with further studies.

Keywords: Gampaha, Sexual abuse, Sri Lanka

Received: 12 May 2021, Revised version accepted: 27 June 2021, Published: 30 June 2021. *Corresponding author: Perera BCS, $\triangle$ email: Chaamindasu@gmail.com

ORCID: https://orcid.org/0000-0001-7762-3060

Cite this article as: Perera BCS. A Retrospective Study on Presentation, Patterns, and the Prevalence of Injuries in Alleged Sexual Assault Cases, Presented to District General Hospital Gampaha from July 2018 to April 2019. 2021;9(1):14-19.

DOI: http://doi.org/10.4038/mljsl.v9i1.7438

Copyright: @ 2019 with the Medico-legal Journal of Sri Lanka.

This is an open-access article distributed under the terms of the Creative Commons Attribution 4.0 International License, which permits unrestricted use, distribution, and reproduction in any medium provided the original author and source are credited.

Introduction

Sexual abuse is an undesired sexual behavior by one person upon another. Perpetrators do this for their stimulation or gratification of another person's like in child pornography.[1,2,3] Although the majority of the victims are females, it can also occur in 
males.[4] In a study done in the USA, one in five women and one in 71 men have been sexually abused at some point in their lives.[5]

Based on WHO report, in 2018 there were about 2000 police cases with sexual abuse.[6] However, there were no published data specific to the Gampaha district and it is the second most populous district of Sri Lanka.[7] District General Hospital (DGH) Gampaha receives referrals for medico-legal examination from eight out of 13 Divisional Secretary divisions in the district.

This study was designed to understand the presentation, pattern, and prevalence of injuries of sexual abuse victims presented to DGH Gampaha from July 2018 to April 2019. The findings of this study will use to identify the different variables that can influence the medico-legal examination, opinion, planning of management, and prevention.

\section{Methodology}

A retrospective descriptive study based on the medico-legal records of all the cases with alleged sexual abuse reported to DGH Gampaha, during the period of 10 months from July 2018 to April 2019 was assessed. Adults and children of both sexes were included and case records with incomplete data were excluded.

Information from the Medico-Legal Examination Forms, Medico-Legal Reports, and other caserelated materials such as Bed Head Tickets of the victims was used to fill the proforma. There was a total of 103 case records included in the study. Data were coded and entered into IBM Statistical Package for Social Sciences (SPSS) version 26 and analyzed using descriptive statistics. Bivariate analysis and multiple logistic regression were calculated where necessary and "P" values and confidence intervals were calculated depending on the variables assessed.

Data transferring to proforma, coding, and entering into statistical package and analysis were done personally by the principal investigator. None of the personal identification data were collected and data stored in a secure official cabinet and only used for the research purpose.

Ethical clearance was obtained from the Ethical Review Committee (ERC) Faculty of Medicine, Ragama, and permission to extract data from the case records were obtained from the Director, DGH Gampaha.

\section{Results}

Socio-demographic characteristics of victims

A total of 103 alleged sexual assault cases, were assessed. $88(85 \%)$ females and $15(15 \%)$ males. The median age of victims was 15 and ages ranged from 3 years to 87 years. (Figure 1) Cases were reported from 17 police divisions from 8 DS. Almost one-quarter $(n=25)$ of cases were reported from the Gampaha police division. $70 \%(\mathrm{n}=72)$ of victims have completed their secondary education and almost $90 \%$ of victims were unmarried.

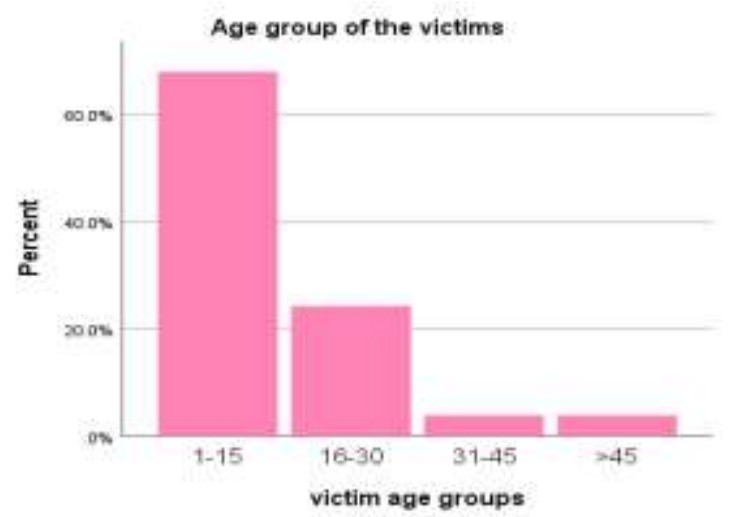

Figure 1: Age distribution of victims

\section{Characteristics of perpetrators}

Almost all the perpetrators were males and the mean age was 31 years $(S D=14$, range 14 to 70$) .61 \%$ of abusers were between 16 to 30 age group and $5 \%$ of them were more than 60 years (Figure 2). Abusers were known persons, not relatives $(82 \%, n=84)$, relative under incest law (law or strangers. There was a $92 \%$ probability of an abuser become a known person or a relative of the victim. $(95 \%$ confidence interval is $85 \%-96 \%$ )

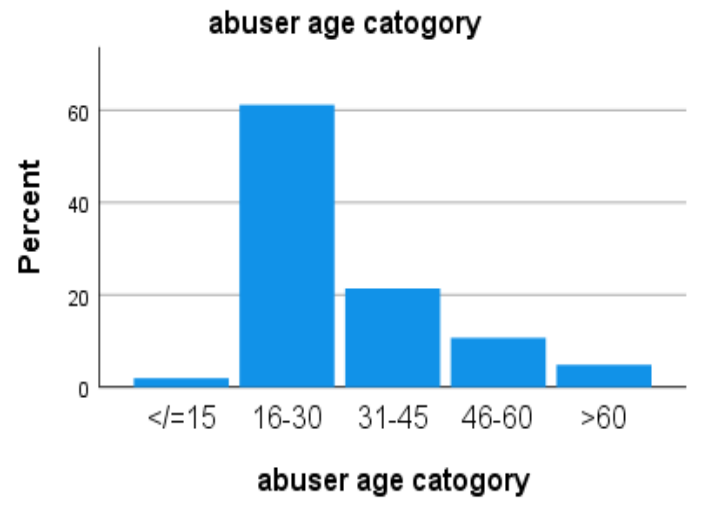

Figure 2: Age distribution of abusers

\section{Presentations and patterns of injuries}

In about $45 \%$ of females, the nature of hymen could not be assessed due to factors like advanced age, previous sexually active state, etc. However, $42 \%$ 
had annular, $11 \%$ fimbriated, and $3 \%$ cresentic hymen types.

Ten percent $(10 \%)(n=10)$ of victims sustained nongenital injuries following a sexual assault with injuries in more than one site. Breast (33\%), head and face $(28 \%)$, and neck $(24 \%)$ are the commonest sites. Abrasions (35\%), bites (18\%), and contusions $(18 \%)$ were the injury type.

$11 \%(\mathrm{n}=11)$ victims had genital injuries and $55 \%$ of them are less than 15 years. All the genital injuries $(\mathrm{n}=11)$ were at the hymen with $90 \%$ hymenal lacerations and $10 \%$ contusions. Common positions of the hymenal injuries were 6 O'clock (50\%) and 03 o'clock $(30 \%)$. Out of the victims with genital injuries, almost $75 \%$ presented within one week or less from the incident.

Only about $03 \%$ of victims $(n=03)$ had anal/perianal anal injuries and all of them were less than 15 -yearold males and none of the male victims had any other physical injury except for that. The injuries were either perianal erythema $(02 \%)$ perianal abrasions $(01 \%)$ or anal tear/lacerations $(01 \%)$. All the victims with anal injuries had reflex anal dilatation.

\section{Nature and location of the sexual abuse.}

About $40 \%(n=40)$ of victims gave a history of repeated abuse ( $20 \%$ males vs. $42 \%$ of females) with no statistically significant difference among the genders (chi-square $=2.6, \mathrm{p}=0.105>0.05$ ). One-fifth of repeated abuse cases have occurred within 1-6 months before the presentation.

The commonest time duration spent per act was 1530 minutes $(61 \%)$ followed by less than 15 minutes (18\%) and almost $90 \%$ of incidences occurred at a smooth location. Almost one-quarter of cases $(n=25)$ complained of ejaculation.

\section{Factors associated with the time duration to present to the hospital}

Almost $60 \%$ of cases presented within 3 days of the incident. The median time to the first presentation from the incidence was 3 days (range $=1$ day to 2.7 years) (Figure 3).

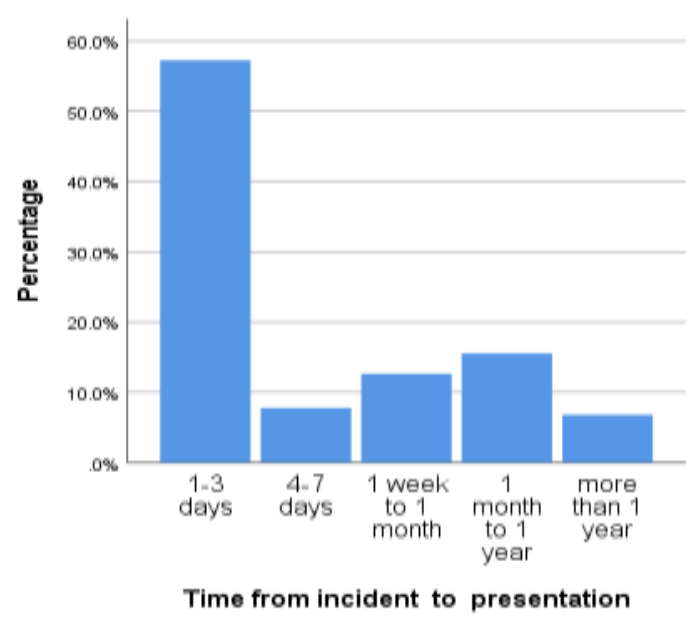

Figure 03: Time taken by victims for the presentation.

On multiple logistics regression, those who had a history of repeated abuse and who became pregnant following the abuse were significantly associated with the length of time to reporting. $(\operatorname{Exp}(\mathrm{B})=$ 3.082; 95\% CI, 1.224 - 7.76; P-value $=0.017<0.05$ and $(\operatorname{Exp}(B)=17.066 ; 95 \%$ CI, $2.001-145.56$, pvalue $=0.009<0.05)$ respectively)

Victim age ( $<15$ vs. $>15)$, place of residence, sex, civil status, type of abuser (known and relative vs. stranger), and presence of injuries were not significantly associated with the time duration to report to the hospital.

However, the prevalence of genital injuries was almost four-fold among the victims that presented within one week or less from the incident compared to those presented after one week.

\section{Health effects of the victims and medico-legal opinion}

All the cases were routinely referred to the Venereologist, and baseline syphilis and HIV serology were negative in all cases. And one case was treated as genital HSV. Follow-up HIV and syphilis serology was planned in 3 months in all cases.

In $5 \%$ of cases, victims had psychological problems even before the incidence and about $07 \%(\mathrm{n}=07)$ of victims were psychologically disturbed after the incidence, according to the psychiatrist.

Sexually assaulted unmarried females have a $13 \%$ (95\% Confidence interval, $06 \%$ - 22\%) chance of getting pregnant and $11 \%$ (95\% Confidence interval, $05 \%-20 \%$ ) chance of being presented with an acute hymenal tare following sexual abuse. 
Regarding medico-legal opinion, $35 \%$ of cases were reported as no physical/medical evidence, followed by chronic vaginal penetration $33 \%$ and acute vaginal penetration $5 \%$.

\section{Discussion}

All age groups are vulnerable to sexual violence. Victims may end up with physical and mental trauma. Sexually transmitted diseases, unwanted pregnancy, and sexual dysfunctions continued to be public health and human rights issues around the world including in Sri Lanka. [5,8]

According to Sri Lanka's first dedicated national survey on physical and sexual violence against women and girls (2019), there was a $02 \%$ prevalence of intimate partner sexual violence and $01 \%$ of none partner sexual violence among 15 years old and above females during the last 12 months.[9] Although there is only a few documented evidence regarding the prevalence of sexual violence against men and boys, the anecdotal reports and scattered evidence regarding such incidence described from diverse settings are not uncommon.[10]

However, studies on prevalence and patterns of injuries following sexual abuse discussed in medicolegal perspectives, especially concerning specific geographic areas of the country are inadequate.

During the 10 months study period, a total of 103 cases were presented, and almost $90 \%$ of them were females. This can be the tip of the iceberg as most cases remain unreported similar to elsewhere in the world.

There can be several reasons for underreporting of the total number of cases as well as markedly low male cases. Minor forms of abuse may not present to the hospital as the victims themselves consider, it was negligible. In addition, attitudes toward the gender norms of the society, and towards violence against females may indirectly influence the presentations. In a women's wellbeing survey, almost half of the women interviewed agreed with male superiority (47\%).[9] Therefore, cases of intimate partner violence may be under-reported. Further, cases of sexual abuse always tend to remain hidden due to the fear of stigmatization, lack of social support, loss of confidence in the justice system, or as a result of the absence of social services and support for survivors. According to the World Health Organization, cultural and traditional male superiority entitlement, the social acceptance of violence against women, inadequate legal and community sanctions against the abusers, areas with social conflicts with increased crimes and poverty are the main risk factors that admire this type of crime throughout the world.[4] Also, male survivors may discourage to come forward due to discrimination and criminalization of same-sex sexual acts leading to be accused of themselves as homosexual activists.[10] Moreover, fear of repercussions both to themselves and to family members remains a significant barrier to reporting sexual abuse in Sri Lanka.

In our study the median age of victims was 15 years. However, according to the women's wellbeing study, the prevalence of sexual violence by non-partner during the last 12 months, was highest among the age group of 35 to $44(01 \%)$. The reason for the deviation may be because it is based on an interview and our study was done using the cases who made a police complaint. Older may reluctant to make an official complaint.

In this study, abusers are almost always male as females are more vulnerable due to their unequal social status. Also, male victims tend to underreport when abusers are females as most of the time it is considered to be an insult when a male is abused by a female. In contrast, females tend to report more due to fear and stigma of loss of virginity and risk of pregnancy.

Most of the abusers were known persons or relatives according to our findings. In another study on child sexual abuse in Sri Lanka, had similar findings, with $83 \%$ of abusers are known to the child.[11] As most of the victims were less than 16 years in our study also, it can be related to the fact that the known persons have more access to minors than strangers. The same reason may be the cause for the significantly higher number of repeated abuse cases $(40 \%)$. Considering the relatives under the incest law, the majority were the father of the victim or the grandfather. Similarly, in another study done in Sri Lanka in 2004, out of 1200 women surveyed, in 9\% of cases, the abuser was the father.[12]

Most of the abusers mainly being 16-45 age group are expected, as it reflects the usual range of the age of sexually active males. This also explains and tally with fact that the male sex hormone (testosterone) usually peaks around the age of 20 and decreases slowly after 30 years. A study done in Ethiopia reflects the same findings as ours about the age distribution of perpetrators.[13]

In $45 \%$ of victims, the nature of hymen could not be assessed due to various other factors like changes of hymen due to previous sexual activeness, attenuation due to chronic vaginal penetration, age-related 
changes, changes due to pregnancy and vaginal delivery, etc. The annular type hymen being the commonest is tallying with the various other studies done all around the world. [14]

Regarding genital injuries, lacerations are the commonest type and the hymen is the commonest site of the injuries. The commonest positions of the hymenal injury were 6 O'clock and 3 O'clock. Other types of injuries were contusions and abrasions. The less than 15year age group had a higher prevalence of genital injuries compared to other age groups. However, this difference was not statistically significant.

The prevalence of victims having a genital injury is about $10 \%$ in our study. However, more than $50 \%$ of them were in the less than 15 years age group, and hymen was the injury site in almost all of them. A study done in Nigeria regarding genital injuries in adolescent rape victims had similar results with $45 \%$ of the victims having genital injuries reflecting the fact that younger victims are more susceptible to genital injuries following an abuse.[15] In contrast, it was $66 \%$ to $85 \%$ among the adolescent victims of sexual assault in two cities in USA.[16] The result may due to the fact that developing countries have limited facilities for a detailed forensic examination than in developed countries. According to a study done in 2005, usage of colposcopy, digital imaging, and staining with contrast media such as toluidine blue, gentian violet, fluorescein, Lugol's solution, has increased the prevalence of genital injuries almost about $90 \%$.[17]

It also can be related to the delayed presentation of the victims, as minor injuries can heal with time before the medical-legal examination. In the Nigerian study, it was also four-fold lower among the victims that presented after 72 hours which is similar to our study and thereby supporting the above fact. [15]

All the victims, who had anal/perianal anal injuries were less than 15-year-old males. All of them had reflex anal dilatation which is suggestive but not confirmative of chronic anal abuse. However, the history didn't support this finding as all of them had denied previous anal intercourse.

In our study, more than one-third of victims gave a history of repeated abuse. However, there is no statistically significant difference between repeated abuses with regard to the gender of victims. The commonest time duration spent per act was 15-30 minutes and almost all the incidences occurred at a smooth location. It may be due to the reason that majority of the victims being children, and most of them were abused by known persons usually in their home environment.

More than half of the victims had presented to medico-legal examination within 3 days of the incident. History of previous or chronic sexual abuse had a significant delay in presentation similar to those who were pregnant compared to non-pregnant counterparts.

Inability to find a statistically significant association between length of time to present with victim age, place of residence, sex, civil status, type of the abuser (known/relative vs. stranger) and presence of injuries may due to smaller sample size. However, the prevalence of genital injuries was almost fourfold among the victims that presented within one week or less compared to those presented later.

Thirteen percent (13\%) of sexually assaulted unmarried females being presented with pregnancy is an important finding of the study which may need evaluation with further studies. Concerning medicolegal opinion, $35 \%$ of cases were reported as no physical evidence, followed by chronic vaginal penetration $33 \%$ and acute vaginal penetration $05 \%$.

The smaller sample size, lack of appropriate instruments for examination, retrospective nature of the study using secondary data may probably have affected the findings and is a limitation. Also, as it was hospital-based, it may not reflect the true prevalence of the general population. However, the validity of the study will not completely be affected by this.

Still, in most of the centers of developing countries, the genital examination carried out only using the naked eye. Therefore, governments need to establish forensic centers with modern technology and facilities to facilitate detailed forensic examination, as the lack of data may strongly influence the opinion of the forensic expert and thereby affect the court procedure when it comes to final judgment.

\section{Conclusions}

The majority of victims were females and the majority of the abusers were males. Known persons or relatives were the most potential abusers. Females less than 16 years of age are the most vulnerable group and had a higher prevalence of genital injuries compared to other age groups. The prevalence of genital injuries was almost four-fold among the victims that presented to the medicolegal examination within one week or less. All the victims, who had anal/perianal injuries were less 
than 15-year-old males. The presence of repeated abuse and presence of pregnancy was significantly associated with the duration of the time to present to the hospital. Thirteen percent (13\%) of sexually assaulted unmarried females being presented with pregnancy is an important finding which may need evaluation with further studies.

\section{Disclosure statement}

Conflicts of interests: The author declares that she has no conflicts of interest.

Funding: None

\section{References}

1. Cameron P, Jelinek G, Kelly A, Brown AFT, Little M. Textbook of adult emergency medicine, 5th ed.:Elsevier;2020.

2. "Sexual abuse". American Psychological Association.

https://www.apa.org/topics/sexual-assaultharassment (accessed 08 June 2021).

3. Kemp CH. Sexual abuse, another hidden pediatric problem. Anderson Aldrich Lecture. Pediatrics 1978 Sep;62(3):382-9.

4. Etienne G,Krug, Linda L, (eds). World report on violence and health. Geneva: World Health Organization;2002. pp. 147-81.

5. Black MC, Basile KC, Breiding MJ, Smith SG. National intimate partner and sexual violence survey: 2010 Summary Report. Atlanta, e National Center for Injury Prevention and Control of the Centers for Disease Control and Prevention; 2010. https://www.cdc.gov/ violenceprevention/pdf/ (accessed 05 June 2021).

6. Country profile on gender-based violence in Sri Lanka. Colombo: World health organization, country office for Sri Lanka;2018.

7. Department of Census and Statistics. http://www.statistics.gov.lk (accessed 09 June 2021).

8. Jina R, Thomas LS. Health consequences of sexual violence against women. Best Pract Res Clin Obstet Gynaecol 2013;27(1):15-26
9. Women's wellbeing survey-2019. Sri Lanka: Department of census and statistics; 2020.

10. Legacies and lessons - sexual violence against men and boys in Sri Lanka and Bosnia \& Herzegovina: All survivors project; 2017. https://williamsinstitute.law.ucla.edu/wpcontent/uploads/Sexual-Violence-Sri-LankaBosnia-May-2017.pdf (accessed 05 June 2021).

11. Rohanachandra YM, Dahanayake DMA, Pathigoda PAS, Wijetunge GS. Characteristics of victims of alleged child sexual abuse referred to a child guidance clinic of a children's hospital. Ceylon medical journal 2015;60 (4):163-4

12. Moonesinghe LN, Rajapaksa LC, Samarasinghe G. Development of a screening instrument to detect physical abuse and its use in a cohort of pregnant women in Sri Lanka. Asia Pac J Public Health. 2004;16(2):138-44

13. Timketa G, Birkneh T, Tigist B. Time to presentation, pattern and immediate health effects of alleged child sexual abuse at two tertiary hospitals in Addis Ababa, Ethiopia. BMC Public Health 2014 Jan 30;14:92

14. Hegazy AA, Al-Rukban MO. Hymen: facts and conceptions. the Health 2012;3(4):109-15

15. Samuel RO, Euzebus CE. Prevalence and pattern of genital injuries among adolescent rape victims attending Enugu state university teaching hospital, South East Nigeria. Journal of Obstetrics and Gynaecology 2018;39(2):190-4

16. Rachel B. Baker, Marilyn S. Sommers. Relationship of Genital Injuries and Age in Adolescent and Young Adult Rape Survivors. J Obstet Gynecol Neonatal Nurs 2008; 37(3):282-9

17. Sommers MS, Fisher B, Karjane H. Using colposcopy in the rape exam: health care, forensic, and criminal justice issues. Journal of forensic nursing 2005; 1(1): 28-34 